\title{
Low cycle fatigue damage model and sensitivity analysis of fatigue crack initiation by finite element approach
}

\author{
Zhi-qiang Wang, Xiao-guang Huang*, Dian-hao Zhang \\ College of Pipeline and Civil Engineering, China University of Petroleum (East China), Qingdao, 266580, China. \\ buangxg@upc.edu.cn, buangxg@upc.edu.cn,918052605@qq.com
}

ABSTRACT. To meet the design requirements, different types of defects are often machined on the surface of fatigue components. Local stress concentration formed at the notch accelerates the initiation of fatigue crack, therefore greatly shortens the service lives of such components. Based on the theory of continuous damage mechanics and the principle of irreversible thermodynamics, the damage evolution model of low cycle fatigue is investigated. By programming the damage evolution model as a UMAT subroutine and coupling it to ABAQUS, the fatigue damage and crack initiation life of notched P92 steel samples under specific loads are simulated, and the crack initiation location is determined. Furthermore, the damage evolution and crack initiation sensitivity of notch morphology are considered. The results show that the crack initiation occurs easily in the notch root where the damage reaches the maximum and the plastic strain accumulates most quickly under cyclic loading. The fatigue damage accumulates slowly at the initial stage, but the damage accumulates rapidly after the cumulative damage reaches a critical value. The fatigue damage evolution and fatigue initiation life are very sensitive to the notch morphology parameters. The notch morphologies need to be analyzed carefully, to improve the fatigue life of the notched samples.

KEYwORDS. Defect; damage evolution model; Low cycle fatigue; Crack initiation; Sensitivity.

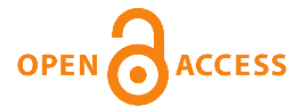

Citation: Wang, Z. Q., Huang, X. G., Zhang, D.H., Low cycle fatigue damage model and sensitivity analysis of fatigue crack initiation by finite element approach, Frattura ed Integrità Strutturale, 53 (2020) 81-91.

Received: 16.12 .2019

Accepted: 09.04.2020

Published: 01.07.2020

Copyright: (C) 2020 This is an open access article under the terms of the CC-BY 4.0, which permits unrestricted use, distribution, and reproduction in any medium, provided the original author and source are credited.

\section{INTRODUCTION}

$\mathrm{F}$ atigue is a common failure behavior of metal materials under an alternating load. With the widespread application of metal materials in automobiles, machinery, aerospace, etc., fatigue failure has gradually become one of the main failure modes of such components [1]. Generally, fatigue failure can be divided into three stages: crack initiation, crack propagation and fracture. For those materials without initial damage, the crack initiation life usually accounts for more than $80 \%$ of the total life. Hence, it is of great significance to study the crack initiation life of metal materials [5].

According to the relationship between stress, strain and fatigue life, the corresponding fatigue life models have been gradually established to solve the high cycle or low cycle fatigue life prediction of the structural components. The Manson- 
Coffin model is commonly used in the low cycle fatigue life prediction [6]. In recent decades, the application of continuous damage mechanics to fatigue damage evolution has been considered as one of the most effective methods to predict fatigue life, and has attracted extensive attentions [8]. Memon [11] studied the influence of loading sequence on the fatigue life using damage mechanics-finite element method, and verified that the damage mechanics-finite element method based fatigue lives were consistent with the experimental results. Tommy et al. [12] proposed the concept that the detailed fatigue damage analysis in some key areas could greatly simplify the calculation process and solve the practical engineering problems effectively. Based on the concept of damage step size, Zheng et al. [13] deduced the fatigue crack nucleation and propagation prediction formula, and predicted the whole life of 2024 and 7075 notched plate specimens with various geometric parameters. Guan et al. [14] proposed a new low cycle fatigue damage evolution model according to the theoretical continuous damage mechanics and energy principle, which was verified to predict the low cycle fatigue life of metal materials effectively. However, to meet the requirements of engineering design, fatigue components inevitably have different notch morphologies. When under cyclic loads, the cracks often initiate at the structural notch on account of the local stress concentration [15]. Therefore, it is extremely important to design the notch shape to improve the fatigue life of the notch members. Xie [16] used the modified Tanaka-Mura model to reveal the effect of gradient hardening thickness on the initiation location and lifetime of fatigue cracks. Xing [17] et al. predicted the crack initiation life of notched plate specimens under high-low cycle fatigue load. However, the influence of notch and its morphology on crack initiation life has attracted very limited attention.

In this paper, the low cycle fatigue damage evolution law derived from the theory of damage mechanics is established and the influence of notch morphology on the crack initiation life of P92 steel is analyzed. In consequence, the low cycle fatigue damage evolution law derived from the theory of continuous damage mechanics is written as a UMAT subroutine and coupled to ABAQUS software in this paper, so as to analyze the influence of different notch morphology on crack initiation life. The analysis results are helpful to the durability design of fatigue parts with notch.

\section{FATIGUE DAMAGE MODEL}

\section{Damage evolution theory}

A ccording to the classical damage theory, damage is usually defined as a phenomenon of deterioration of the internal properties of materials caused by the generation of micro-cracks and micro-cavities under external loads. By introducing the damage definition of Lemaitre [18], the damage variable $D$ for uniaxial samples can be expressed as follows:

$$
D=1-S_{\mathrm{D}} / S
$$

where $S_{\mathrm{D}}$ and $S$ represent the effective bearing area of the damaged material, and the cross-sectional area of the material under no damage, respectively. There is no damage to the material when $D=0$, whereas, the material completely fails when $D=1$.

Fatigue damage is always caused by the cumulative plastic strain. According to the continuous damage theory, the low cycle fatigue damage can be performed by an energy dissipative potential, i.e.

$$
\varphi=\varphi\left(\varepsilon, T, \varepsilon^{\mathrm{e}}, \varepsilon^{\mathrm{p}}, \varepsilon_{\mathrm{a}}^{\mathrm{p}}, D, \ldots\right)
$$

where $\varepsilon$ is the total strain, $T$ is the temperature, $\varepsilon^{\mathrm{e}}, \boldsymbol{E}^{\mathrm{p}}$, and $\varepsilon_{a}^{\mathrm{p}}$ represent the elastic, plastic and accumulative strain, respectively.

And the fatigue damage evolution can be derived from the established energy dissipative potential. Based on the theory of continuous damage mechanics, the damage evolution dynamics law can be written as

$$
\dot{D}=-\frac{\partial \varphi}{\partial Y}
$$

where $Y$ denotes strain energy release rate.

In general, the expression of dissipative potential is 


$$
\varphi=\frac{Y^{2}}{2 S_{0}} \cdot \frac{\dot{P}}{(1-D)^{a_{0}}}
$$

where $S_{0}$ and $\alpha_{0}$ are the material constants, and $\dot{P}$ represents the plastic strain rate.

Correspondingly, the strain energy release rate $Y$ is demonstrated as follows:

$$
Y=\frac{\sigma_{\mathrm{eq}}^{2} R_{\mathrm{V}}}{2 E(1-D)^{2}}
$$

where $\sigma_{\text {eq }}$ and $E$ denote the equivalent stress and Young's modulus, respectively, and $R_{\mathrm{V}}$ is the parameter describing the triaxial stress effect with the following expression:

$$
\mathrm{R}_{\mathrm{V}}=\frac{2}{3}(1+v)+3(1+2 v)\left(\frac{\sigma_{\mathrm{H}}}{\sigma_{\text {eq }}}\right)^{2}
$$

with $v$ being the Poisson's ratio, and $\sigma_{\mathrm{H}}$ representing the average stress.

By substituting Eqns. (4)-(5) into Eqn. (3), the fatigue damage evolution law can be obtained as

$$
\dot{D}=\frac{\sigma_{\text {eq }}^{2} \dot{P}}{2 E S_{0}(1-D)^{a_{0}+1}} R_{\mathrm{V}}
$$

Assuming that the stress-strain relationship of the material under cyclic loading can be characterized by the RambergOsgood cyclic constitutive model, so the plastic strain of each stable cycle is

$$
\frac{\Delta P}{2}=\left(\frac{\Delta \sigma}{2 K}\right)^{1 / n}
$$

where $\Delta P$ and $\Delta \sigma$ represent cyclic strain amplitude and cyclic stress amplitude respectively, $K$ is cyclic strength coefficient and $n$ denotes cyclic strain hardening index.

By introducing the concept of damage, the plastic strain per cycle under a proportional loading or uniaxial stress can be rewritten as

$$
\frac{\Delta P}{2}=\left[\frac{\Delta \sigma_{\mathrm{eq}}}{2 K(1-D)}\right]^{1 / n}
$$

The change of damage is very small in a cycle, therefore, the damage variable $D$ is approximately considered as an invariant. Differentiating both sides of Eqn. (9), one can obtain the plastic strain rate expressed as

$$
\mathrm{d} \boldsymbol{P}=\frac{1}{n K(1-D)}\left[\frac{\sigma_{\text {eq }}}{K(1-D)}\right]^{1 / n-1} \mathrm{~d} \sigma_{\text {eq }}
$$

For a symmetric fatigue cycle, the hysteresis loop is centrosymmetric. By integrating Eqn. (7) in one stress cycle and bringing Eqn. (10) into it, the low-cycle fatigue damage per cycle can be obtained 


$$
\frac{\mathrm{d} D}{\mathrm{dN}}=\frac{\left(\Delta \sigma_{\mathrm{eq}}\right)^{1 / n+2} \mathrm{R}_{\mathrm{V}}}{n E S_{0} K^{1 / n}(1-D)^{1 / n+1+a_{0}}(2 n+1)}
$$

Hence, the expression of fatigue damage accumulation per cycle combined with Eqn. (9) is given as follows:

$$
\frac{\mathrm{d} D}{\mathrm{~d} N}=\frac{K^{2} \Delta P^{2 n+1}}{2 E S_{0}(1-D)^{a_{0}}(2 n+1)} \mathrm{R}_{\mathrm{V}}=\frac{\Delta P^{\gamma+1}}{\Omega(\gamma+1)(1-D)^{a_{0}}} \mathrm{R}_{\mathrm{V}}
$$

where $\Omega$ and $\gamma$ are the material constants, $\Omega=\frac{2 E S_{0}}{K^{2}}, \gamma=2 n[19]$.

\section{DAMAGE EVOLUTION SIMULATION BY FINITE ELEMENT APPROACH AND THE IMPLEMENTATION METHOD}

$\mathrm{I}$

$\mathrm{n}$ this paper, the bilaterally notched plate specimens of P92 steel were selected to simulate the fatigue damage evolution and analyze the influence of notch morphology on fatigue crack nucleation life. Three main notch shapes, namely, Cnotched, $\mathrm{U}$-notched and $\mathrm{V}$-notched are included. To describe the notch clearly $H, \theta$, and $\mathrm{R}$, which respectively mean the notch depth, the opening angle, and the root radius, are adopted to describe the notch type, as shown in Fig. 1. Different values of parameters correspond to different types of notch: the notch is $\mathrm{V}$-notched when the opening angle is greater than 0 . While the opening angle is equal to 0 and the depth is greater than the radius of the root, the notch belongs to U-notched, otherwise it is called a C-notched. The mechanical properties of P92 steel are listed in Tab. 1 [21]. Moreover, the cyclic load with a stress range of $131 \mathrm{MPa}$ and stress ratio of -1 is applied to the ends of the sample, as shown in Fig. 2.

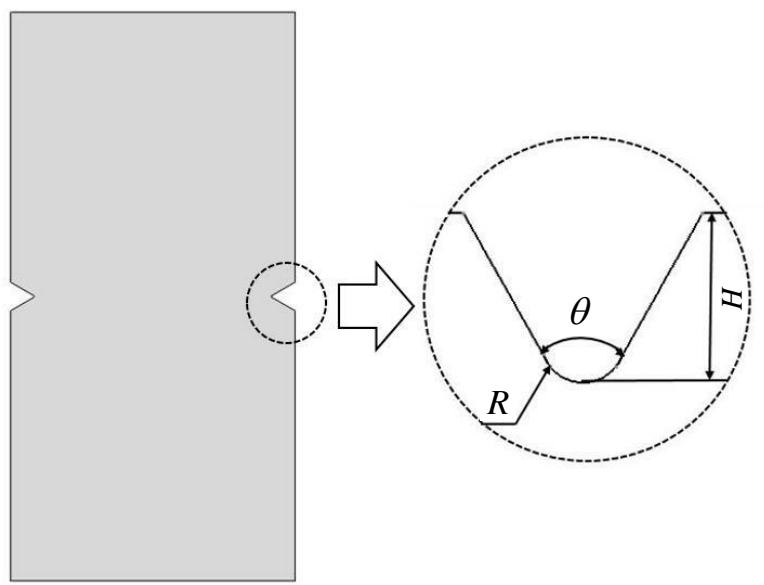

Figure 1: The morphology of symmetrically notched specimen.

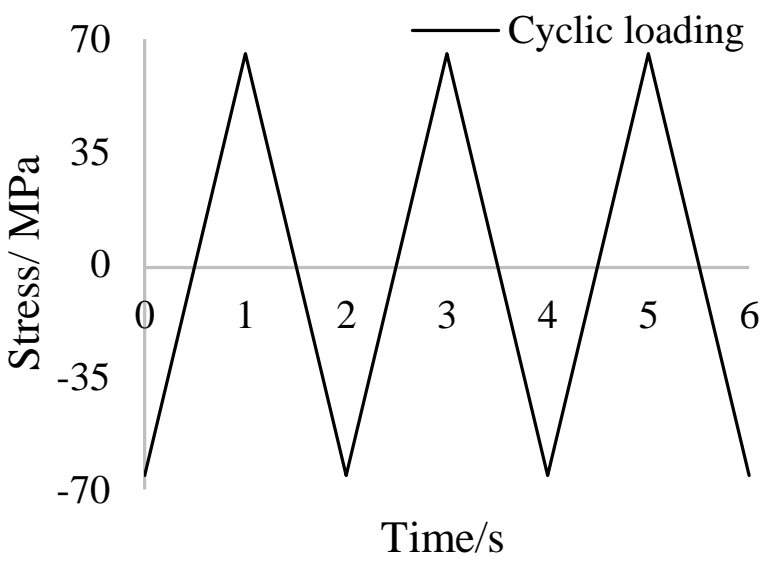

Figure 2: Schematic diagram of loading model.

\begin{tabular}{lccccccc}
\hline Parameter & $E(\mathrm{MPa})$ & $v$ & $K$ & $n$ & $\Omega$ & $\gamma$ & $\alpha_{0}$ \\
Value & 125000 & 0.3 & 234 & 0.119 & 12.57 & 0.273 & 7.56 \\
\hline
\end{tabular}

Table 1: The mechanical property of P92.

Under the fatigue loading, the damage in each element accumulates with the loading cycles. When the damage of the element reaches 1 , the element fails and the micro fatigue crack initiates. Since there is no identical engineering standard for critical crack length for crack initiation, micro-crack length up to $0.1-0.2 \mathrm{~mm}$ is usually referred to the initiation size of crack [22. In this paper, the crack initiation life of notched specimen is studied by coding a UMAT subroutine of the fatigue damage 
evolution law derived above. Crack initiation is considered when the failure element size reaches a critical crack initiation size. The calculation flow chart of ABAQUS UMAT subroutine is shown in Fig. 3.

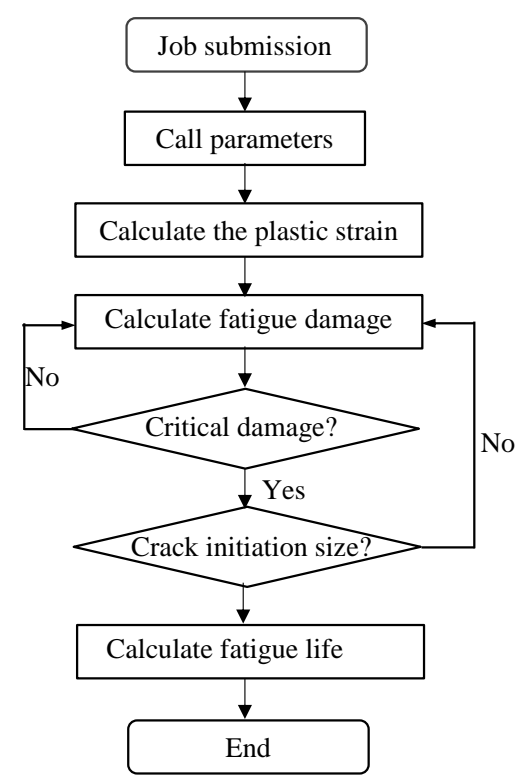

Figure 3: UMAT calculation flow chart.

\section{NUMERICAL SIMULATION OF FATIGUE DAMAGE}

\section{FEM results}

he finite element $1 / 8$ model of plate sample with length of $40 \mathrm{~mm}$, width of $20 \mathrm{~mm}$, thickness of $5 \mathrm{~mm}$ and a bilateral semicircular notch (C-notched, $\mathrm{R}=3 \mathrm{~mm}$ ) in the middle was established, as shown in Fig. 4. The symmetric constraints were applied in the directions of model $\mathrm{x}, \mathrm{y}$ and $\mathrm{z}$. The solid model was divided into a series of three dimensional 8-node reduced integration (C3D8R) elements. To verify the effect of element size on calculation accuracy, a convergence analysis was conducted. We found the analysis results were enough accurate when the mesh size near the notch root is refined to $0.02 \mathrm{~mm}$. The maximum stress, plastic strain state of this model at the first cycle are shown in Figs. 5-6, respectively. The stress and strain concentrations are obvious, because the Mises stress and plastic strain at the notch root are $129.9 \mathrm{MPa}$ and $4.2 \mathrm{e}-5$, respectively. The accumulation of plastic deformation per cycle promotes the continuous evolution of fatigue damage, and the accumulated fatigue damage at the middle of the notch root firstly reach 1 , indicating the fatigue crack firstly initiates from this position, as shown in Fig. 7.

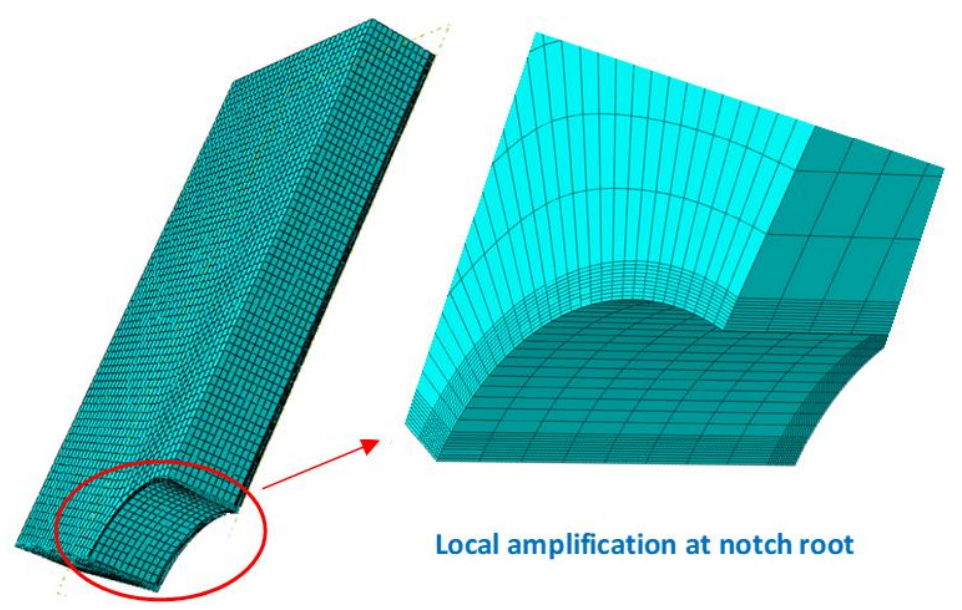

Figure 4: The 1/8 FEM model. 

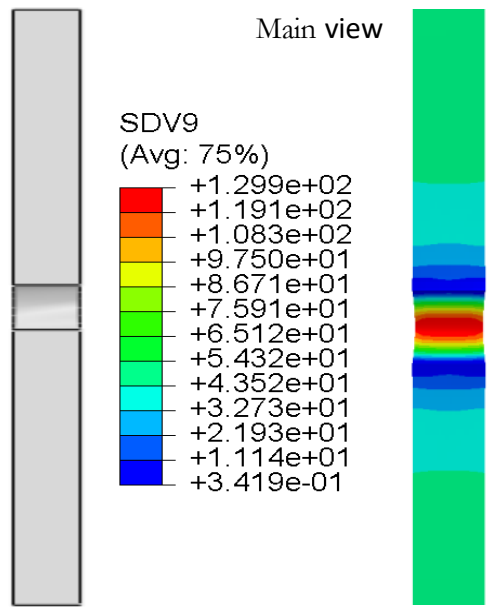

\section{Lateral view}

SDV9

(Avg: 75\%)

$+1.299 \mathrm{e}+02$

$+1.191 \mathrm{e}+02$

$+1.083 e+02$

$+9.750 \mathrm{e}+01$

+8.671e+01

$+7.591 \mathrm{e}+01$

$+6.512 \mathrm{e}+01$

$+5.432 \mathrm{e}+01$

$+4.352 \mathrm{e}+01$

$+3.273 \mathrm{e}+01$

$+2.193 \mathrm{e}+01$

$+1.114 \mathrm{e}+01$

$+3.419 \mathrm{e}-01$

Figure 5: The stress distribution.
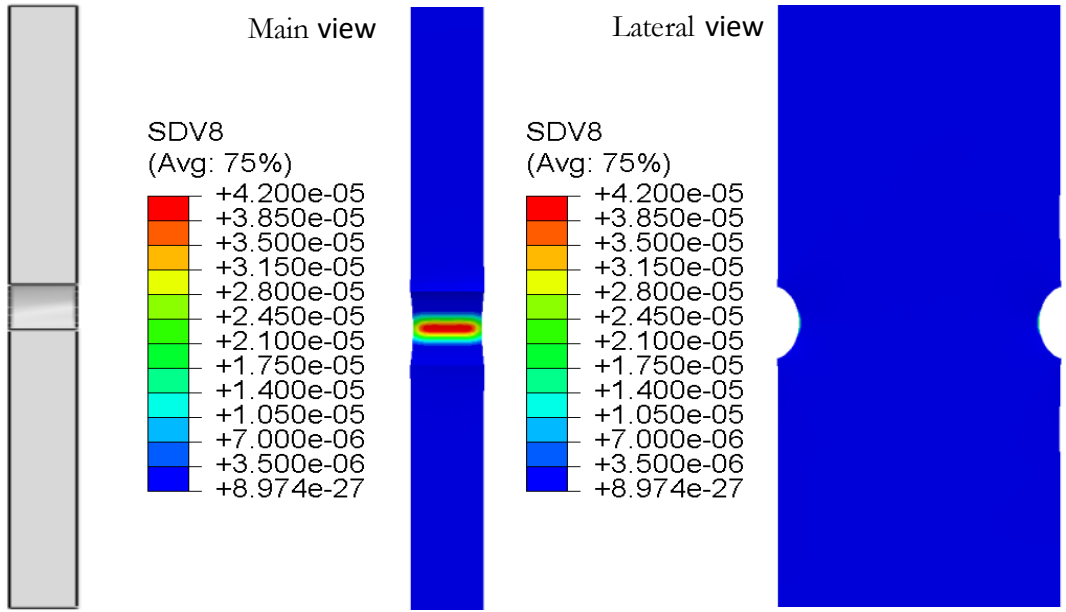

Figure 6: The plastic strain distribution.
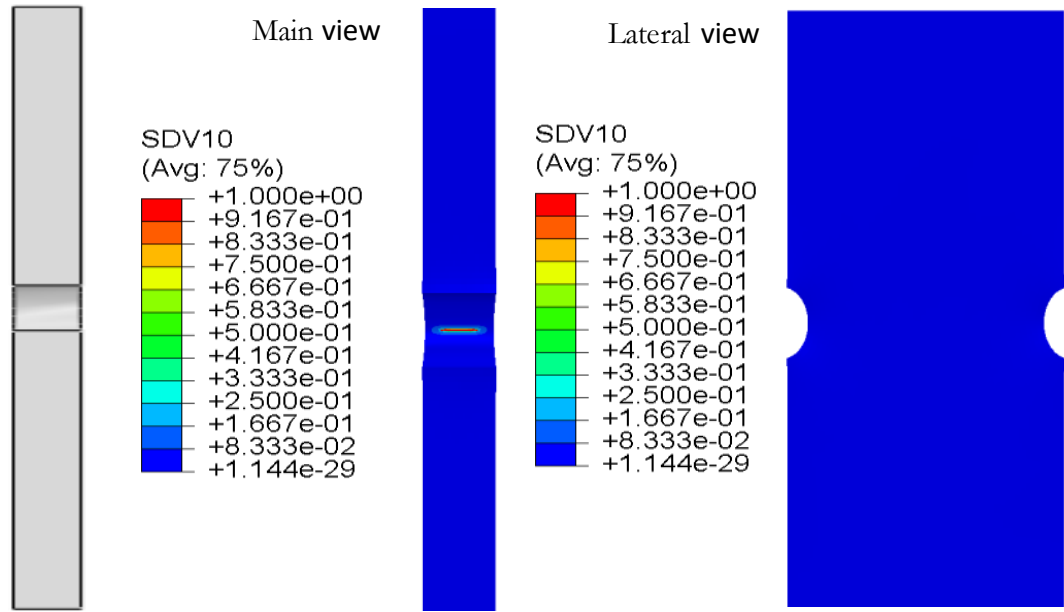

Figure 7: The fatigue damage distribution. 


\section{PARAMETRIC STUDY}

$\mathrm{F}$

ig. 8 shows the fatigue damage accumulation of semi-circular notched specimen with cycle numbers. The notch depth is $2 \mathrm{~mm}$ and the root radii are $2 \mathrm{~mm}, 3 \mathrm{~mm}$, and $4 \mathrm{~mm}$, respectively. We can see that the fatigue damage accumulation is very dependent on the notch root radius, and more fatigue loading cycles are needed to reach a certain damage under a bigger root radius. All the damages accumulate very slowly at the primary stage, whereas, as the number of cycles increases, the damage accumulation also accelerates until the failure of the unit at the critical damage stage. Fig. 9 illustrates the fatigue damage evolution with different notch depths. The influence of notch depth on fatigue damage is as similar as that of the notch radius, which can be contributed to this result that the notch depth and root radius are the most important parameters deciding the stress and strain concentration effect, as well as the damage evolution.

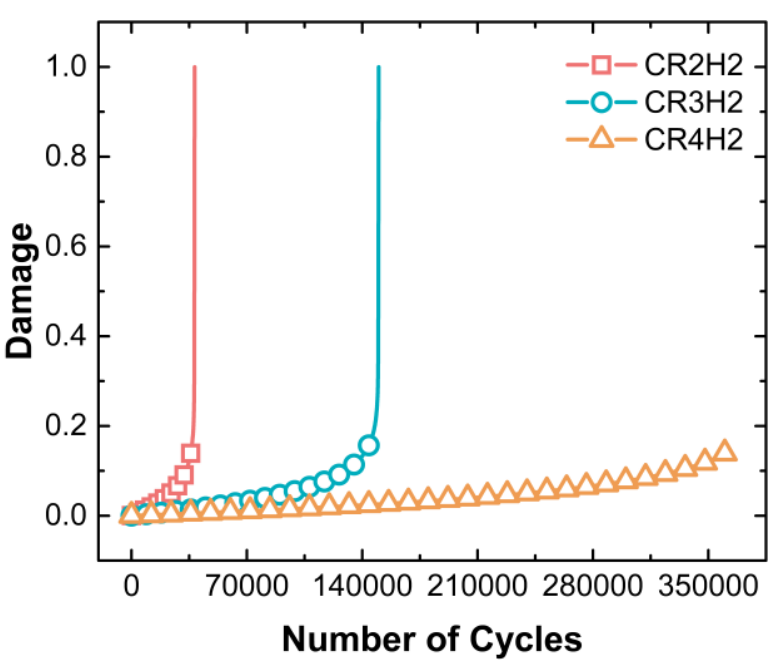

Figure 8: Fatigue damage at different root radius.

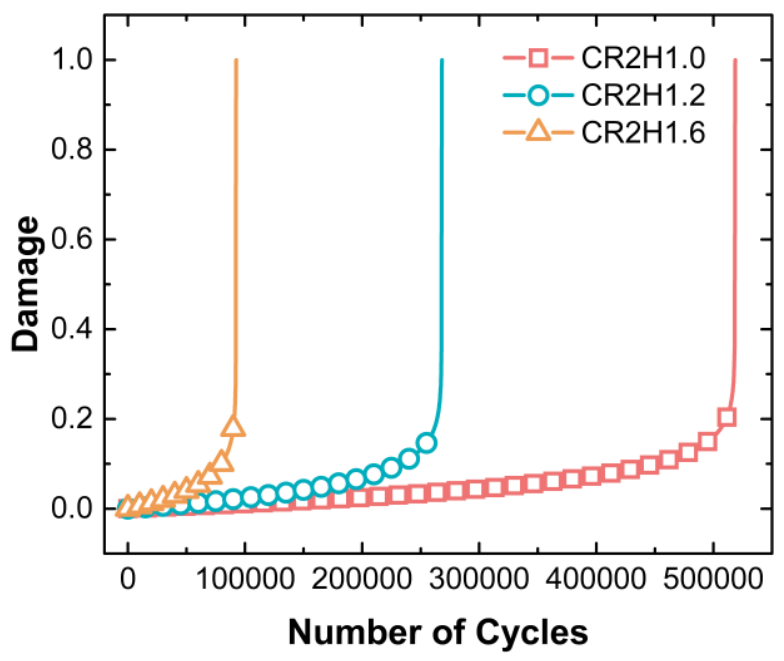

Figure 9: Fatigue damage at different root depths.

Besides, the damage distribution and cyclic plastic strain distributions in the $\mathrm{N}, \mathrm{Z}$ and $\mathrm{X}$ directions of the C-notched specimen with $R=3 \mathrm{~mm}$ and $H=2 \mathrm{~mm}$ are extracted respectively, as shown in Figs. 10-11, where $\mathrm{O}$ is the center of the sample. As can be seen, the maximum value occurs when the displacement is 0 , i.e. the central position of the notch root. The variation trend of the fatigue damage in the three directions is similar, i.e., the damage decreases rapidly with the increase of the distance away from the center. The results indicate that the damage of the notch root element is the largest during the process of cyclic loading, and crack will initiate at the notch root first. The plastic strain distributions in three direction are similar as that of damage, which is consistent with the fatigue damage theory. 


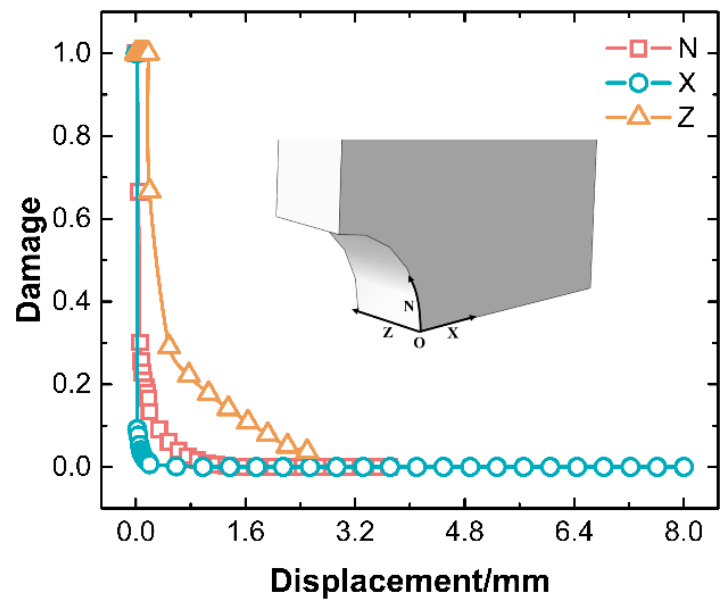

Figure 10: Fatigue damage in different directions.

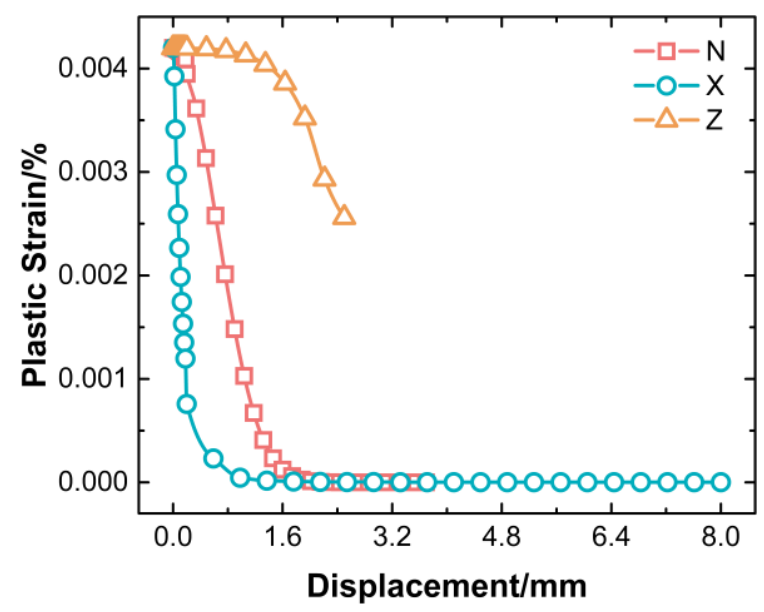

Figure 11: Plastic strain in different directions.

Furthermore, the fatigue damage of $\mathrm{U}$-notched sample is also discussed. Three types of $\mathrm{U}$-notched, i.e., $H=1.5 \mathrm{~mm}, 2.0 \mathrm{~mm}$, and $2.5 \mathrm{~mm}$ were selected to investigate the effect of notch depth $H$ on crack initiation life. The variation in the damage with the cycle number as shown in Fig. 12, where the radius is maintained as $1 \mathrm{~mm}$. It can be clearly noted that the specimen with a notch depth of $2.5 \mathrm{~mm}$ gets to critical damage value at about 1200 cycles, while the specimen experienced almost no damage even after 3000 cycles when the notch depth decreases to $1.5 \mathrm{~mm}$. However, as seen in Fig. 13, the fatigue crack initiation seems to be more sensitive to the notch depth, when compared with Fig. 12.

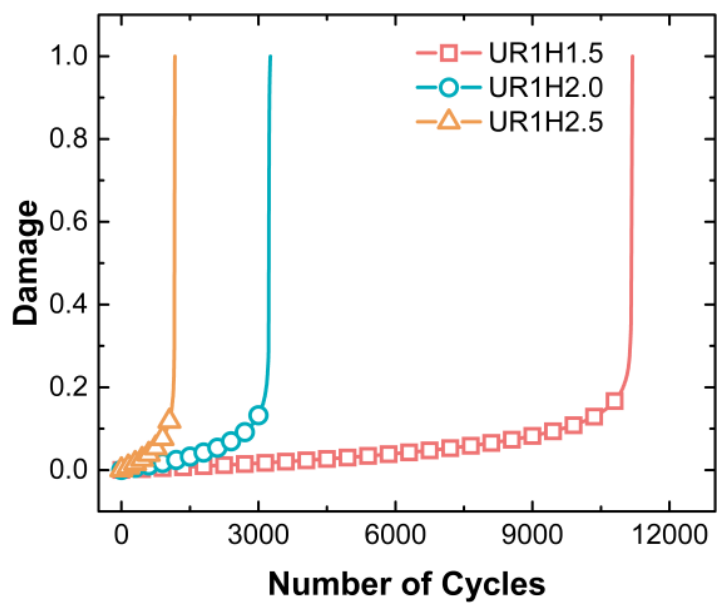

Figure 12: Fatigue damage in different notch depths (U-notched). 


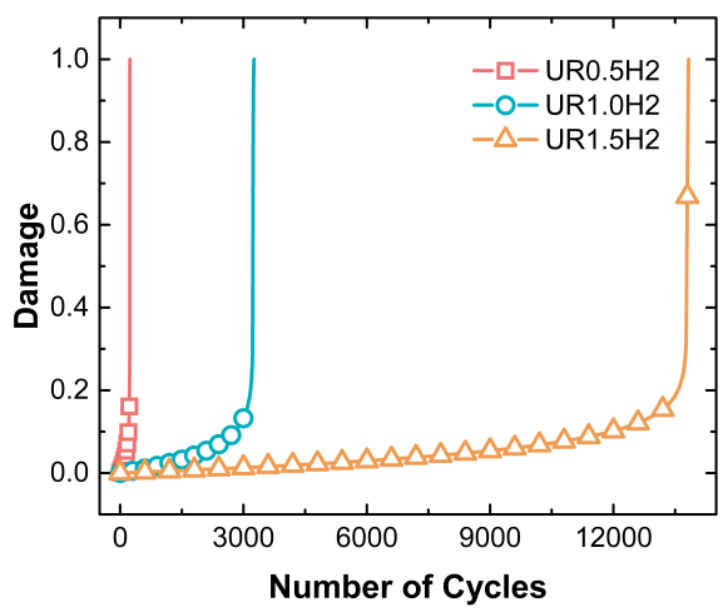

Figure 13: Fatigue damage in different notch radii (U-notched).

Fig. 14 demonstrates the influence of notch dimension on the fatigue damage evolution of $\mathrm{V}$-notched samples. As shown in Fig. 14(a), with the decrease of opening angle, the stress concentration increases and the fatigue damage undergoes rapid evolution accordingly. Fig. 14(b) shows the influence of notch depth on the damage evolution $\left(\theta=90^{\circ}\right)$ and Fig. 14(c) depicts the influence of root radius on the damage evolution $(H=2 \mathrm{~mm})$. Comparative analysis shows that the fatigue damage evolution of among the $\mathrm{V}$-notched sample are very sensitive to the three mentioned notch morphology parameters. In other words, the reasonable notch morphology is needed to improve the fatigue life of this notched sample.

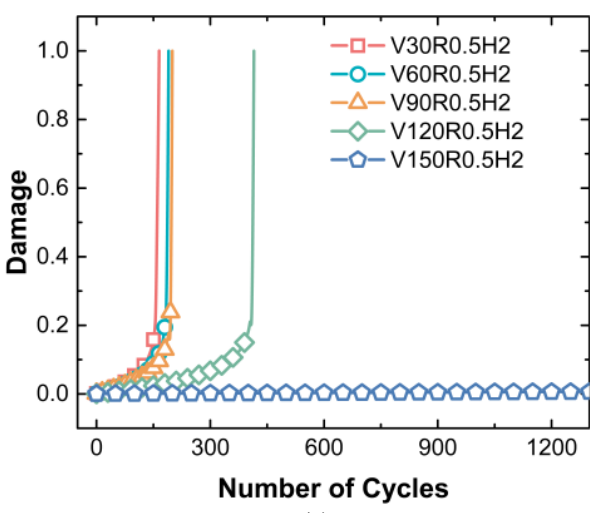

(a)

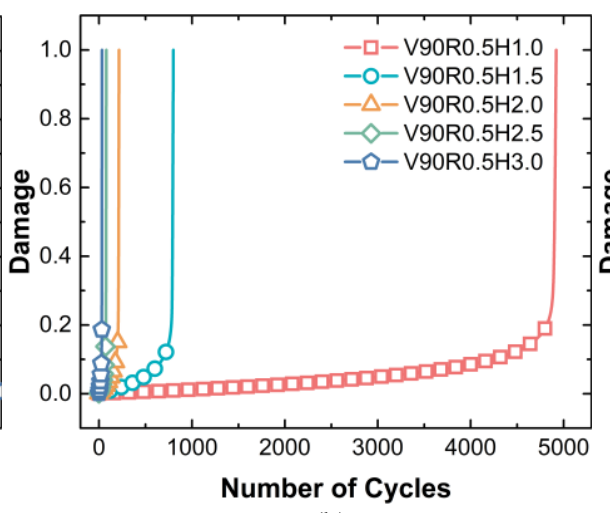

(b)

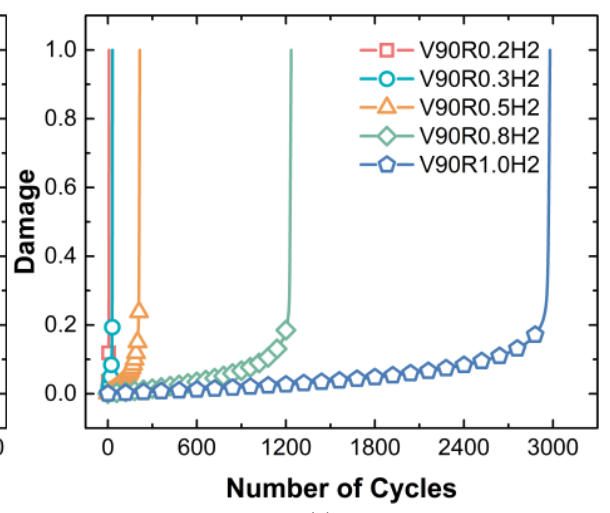

(c)

Figure 14: Fatigue damage evolution of V-notched samples: (a) notch angle, (b) notch depth, (c) notch radius.

\section{CONCLUSIONS}

B ased on the theory of continuous damage mechanics and the principle of irreversible thermodynamics, the damage evolution model of low cycle fatigue is investigated. By programming the damage evolution model with ABAQUS UMAT subroutine, the fatigue damage evolution and crack initiation life of symmetrically notched P92 steel samples under cyclic loads are simulated, and the following conclusions obtained are listed as follows:

(1) The maximum fatigue damage always occurs at the root of the notch, no matter what the notch morphology is. The variations of equivalent stress and cyclic plastic strain along different direction of notch are consistent with that of the fatigue damage.

(2) The fatigue damage accumulates slowly at the initial stage, but the damage accumulates rapidly with the number of cycles after the cumulative damage reaches a critical value.

(3) No matter what type the notch is, the fatigue damage evolution and fatigue initiation life are very sensitive to the notch morphology parameters. The fatigue nucleation lives decrease with the increase of $\mathrm{H} / \mathrm{R}$ in $\mathrm{C}$ and $\mathrm{U}$ notched samples, and the fatigue nucleation lives of $\mathrm{V}$-notched samples are more sensitive to opening angle than root radius and notch depth. 
Therefore, to improve the fatigue life of the notched sample, the notch morphology need to be carefully designed.

\section{ACKNOWLEDGMENTS}

he research work was supported by the Fundamental Research Funds for the Central Universities of China (No.17CX02065), and the National Natural Science Foundation of China (No.51404286).

\section{REFERENCES}

[1] Xu J. Q. (2017). Mechanics of Fatigue. Beijing: Science Press. (in Chinese)

[2] Chow C. L., Wei Y. A model of continuum damage mechanics for fatigue failure. International Journal of Fracture, 1991, 50 (4), pp. 301-316. DOI: 10.1007/bf00032199.

[3] Fatoba O., Akid R. (2018). Uniaxial cyclic elasto-plastic deformation and fatigue failure of API-5L X65 steel under various loading conditions. Theoretical and Applied Fracture Mechanics, 94, pp. 147-159.

DOI: 10.1016/j.tafmec.2018.01.015.

[4] Song W., Liu X., Berto F., Wang P., Fang H. (2012). Fatigue failure transition analysis in load-carrying cruciform welded joints based on strain energy density approach. Fatigue \& Fracture of Engineering Materials \& Structures 40(7), pp. 1164-1177. DOI: $10.1111 /$ ffe.12588.

[5] Huang X.G., and Xu J.Q. (2012). Pit morphology characterization and corrosion fatigue crack nucleation analysis based on energy principle. Fatigue \& Fracture of Engineering Materials \& Structures, 35(7), pp.606-613.

DOI: 10.1111/j.1460-2695.2011.01654.x.

[6] Wang, Y.Y., and Susmel, L. (2016). The modified Manson-Coffin curve method to estimate fatigue lifetime under complex constant and variable amplitude multiaxial fatigue loading. International Journal of Fatigue, 83(2), pp. 135149. DOI: $10.1016 /$ j.jifatigue.2015.10.005.

[7] Zhu S. P., and Huang H. Z., (2010). A generalized frequency separation-strain energy damage function model for low cycle fatigue-creep life prediction. Fatigue \& Fracture of Engineering Materials \& Structures, 33(4), pp. 227-237.

DOI: 10.1111/j.1460-2695.2009.01431.x.

[8] Herwig, M. (2009). Fatigue damage of low amplitude cycles in low carbon steel. Journal of Materials Science, 44, pp. 4919-4929. DOI: 10.1007/s10853-009-3751-x.

[9] Volkov, I.A., Korotkikh, Y.G., Tarasov, I.S., and Shishulin D. N. 2011. Numerical modeling of elastoplastic deformation and damage accumulation in metals under low-cycle fatigue conditions. Strength of Materials, 43, pp. 471485. DOI: $10.1007 / \mathrm{s} 11223-011-9317-6$.

[10] Chen, H. Shang, D. G., Tian, Y. J., and Liu J. Z. (2012). Comparison of multiaxial fatigue damage models under variable amplitude loading. Journal of Mechanical Science and Technology, 26(11), pp. 3439-3446.

DOI: 10.1007/s12206-012-0872-y.

[11] Memon, I. R., Zhang, X., and Cui, D.Y., (2002). Fatigue life prediction of 3-D problems by damage mechanics with two-block loading. International Journal of Fatigue, 24(1), pp. 29-37. DOI: 10.1016/s0142-1123(01)00057-3.

[12] Tommy, H.T., Chan, L., and Guo, L., (2003). Finite element modelling for fatigue stress analysis of large suspension bridge. Journal of Sound and Vibration, 261(3), pp. 443-464. DOI: 10.1016/s0022-460x(02)01086-6.

[13] Zhang, Y.J., Zhang, M., and Hu, W.P., (2011). Fatigue life prediction of the joint plate based on damage mechanics method. Journal of Mechanical Strength, 33(3), pp. 443-449. (in Chinese)

[14] Guan, D., Sun, Q., and Yang, F. P., (2013). A modified low cycle fatigue damage model for metals. Chinese Journal of Solid Mechanics, 34(6), pp. 571-578. (in Chinese)

[15] Bao, Z.Q., (2014). Effect of notch geometry to high cycle fatigue strength of TC4 and prediction. Dissertation of Nanjing University of Aeronautics and Astronautics, Nanjing. (in Chinese)

[16] Xie, J.J. (2017) Numerical simulation study on fatigue life of notch specimens with surface gradient reinforcement. Journal of Aeronautical Materials, 37, 41-49. DOI: 10.11868/j.issn.1005-5053.2017.000094. (in Chinese) 
[17] Xing, J., Han, Y.D., Xu, L. C., Jin, Z. H., Li, C. C., and Zhao, L. (2017). High cycle and low cycle hybrid fatigue damage based on continuum damage mechanics. Transactions of the China Welding Institution, 38(7), pp. 63-66.

DOI: $10.12073 /$ j.hjxb.20150708001.

[18] Lemaitre, J. (1990). Mechanics of solid material. Cambridge University Press, Cambridge.

[19] Yang, X. H., Li, N., Jin, Z. H., and Wang, T. J., (1997). A continuous low cycle fatigue damage model and its application in engineering materials. International Journal Fatigue, 19(10), pp. 687-692. DOI: 10.1016/S0142-1123(97)00102-3.

[20] Song, S., Han, Y.D., Xu, L.Y., Jing, H.Y., Zhao, L., (2019), Analysis on low cycle fatigue damage of Ti-6Al-4V based on combined hardening model. Transactions of the China Welding Institution, 40(1): 43-49. (in Chinese)

[21] Kannan, R., Sankar, V., Sandhya, R., and Mathew, W. D., (2013). Comparative evaluation of the low cycle fatigue behaviours of P91 and P92 steels. Procedia Engineering, 55, pp. 149 -153. DOI: 10.1016/j.proeng.2013.03.234.

[22] Goodall, I. W., and Ainsworth, R.A., (2003). R5: Assessment procedure for the high temperature response of structure (Issue 3). British Energy, Gloucester, UK.

[23] Goodall, I. W., and Ainsworth, R.A., (1991). An assessment procedure for the high temperature response of structures. In: Życzkowski M. (eds) Creep in Structures. International Union of Theoretical and Applied Mechanics. Springer, Berlin, Heidelberg. DOI: 10.1007/978-3-642-84455-3_35. 